Таблица 1. Проблемы управления инновационным развитием горных предприятий. Table 1. Issues of management of mining enterprises' innovative development.

\begin{tabular}{|c|c|}
\hline Проблема & Причины проблемы \\
\hline Отторжение изменений у менеджмента & $\begin{array}{l}\text { У менеджмента не сформирована потребность в инновациях. Стимулирование } \\
\text { производится за счет точечных материальных выплат }\end{array}$ \\
\hline $\begin{array}{l}\text { Изменения проводятся эпизодически, } \\
\text { фррагментарно }\end{array}$ & $\begin{array}{l}\text { Инновационные преобразования несистемны и не согласованы. Оценка } \\
\text { необходимости внедрения инноваций диаметрально различается для работников } \\
\text { различных уровней управления }\end{array}$ \\
\hline $\begin{array}{l}\text { Планируемая динамика улучшений } \\
\text { по процессам не достигается }\end{array}$ & $\begin{array}{l}\text { Структура взаимодействия персонала не изменяется, синергетический эффект } \\
\text { отсутствует }\end{array}$ \\
\hline $\begin{array}{l}\text { Начатый процесс улучшений имеет } \\
\text { тенденцию к остановке }\end{array}$ & $\begin{array}{l}\text { Инновации приводят к повышению неопределенности деятельности на всех уровнях } \\
\text { управления }\end{array}$ \\
\hline $\begin{array}{l}\text { Перекладывание ответственности } \\
\text { с менеджмента на операторов }\end{array}$ & $\begin{array}{l}\text { Не формируются и не реализуются стандарты функционала менеджмента: уровень } \\
\text { ответственности должен отражать уровень управления }\end{array}$ \\
\hline
\end{tabular}

инновации, не совпадают с интересами будущих пользователей инновации (начальник участка, операторы и т. д.) [10].

То есть наблюдается дисбаланс экономических и социальных интересов субъектов, разрабатывающих и реализующих стратегии развития предприятия [11].

Целью работы является формирование типовых стратегий социально-экономического развития горнодобывающего предприятия в зависимости от динамики внешней и внутренней среды. Для устранения несоответствия между необходимостью непрерывного развития и интересами менеджмента любые преобразования должны осуществляться в соответствии с траекторией, которая определяется целями субъектов предприятия с учетом обеспечения устойчивости в краткосрочном и долгосрочном периодах. Траектория развития определяет тип стратегии, учитывающей структуру и особенности предприятия, технико-технологический уклад и достигнутый уровень технико-экономических параметров. Выбор стратегии предопределяется потенциалом и текущими возможностями предприятия с учетом с условий и рисков внешней среды.

Теоретические предпосылки и методология работы

Стратегия связывает прошлое, настоящее и будущее, обозначая путь к развитию: объединяет цели предприятия и программу действий, направленных на их достижение [12]. В рамках нашего исследования стратегия рассматривается как управленческая модель, в которой определены взаимосвязи целей и алгоритмов их достижения; оценены условия и ограничения, обеспечивающие устойчивость развития предприятия при отклонениях параметров внешней и внутренней среды [13].

В основе разработки стратегии социальноэкономического развития лежат базовые концептуальные положения:

- стратегический план согласован с целями собственника, его видением будущего и содержит систему целевых показателей, которые, дополняя друг друга, описывают будущий образ предприятия;

- стратегическое планирование осуществляется на основе дерева целей и программы действий, определяющей функционирование и развитие в долгосрочном периоде;

- содержание стратегического плана составляет совокупность проектов и программ действий на долгосрочную перспективу, направленных на достижение стратегических целей;

- отправным ориентиром при разработке стратегического плана является достигнутая позиция предприятия во внешней среде и по отношению к конкурентам, а также стадия развития внутренней среды. Для горнодобывающего предприятия важным факторов выбора стратегии развития является наличие ресурсной базы;

- стратегия содержит набор альтернативных вариантов, основанных на прогнозе вероятностных сценариев будущего, который имеет высокую степень неопределенности;

- стратегические инициативы, программы, проекты должны ориентироваться на баланс экономических и социальных интересов всех субъектов предприятия, затронутых стратегией.

Формирование стратегии социально-экономического развития горнодобывающего предприятия предполагает не только разработку взаимоувязанных документов, отражающих направление и приоритеты его развития, но и подготовку научно-методического, нормативного, финансового, информационного и административного обеспечения всех процессов [14]. Целевая функция управления развитием на каждом этапе реализации стратегии заключается в обеспечении эффективности и устойчивости предприятия (экономическая составляющая) при соблюдении баланса интересов субъектов (социальная составляющая) [15, 16]. Например, капиталоемкие преобразования на этапе доработки запасов минерального сырья могут оказаться экономически нецелесообразными, а результативность программы действий в существенной степени определяться динамикой внешней среды (прежде всего, факторы конъюнктуры рынка, а также волатильность макроэкономических процессов). Важнейшей составляющей является отражение мотивационного механизма для субъектов, реализующих стратегию 
Таблица 2. Элементы стратегии социально-экономического развития по типам.

Table 2. Elements of the strategy of socio-economic development by type.

\begin{tabular}{|c|c|c|c|c|}
\hline Тип стратегии & $\begin{array}{c}\text { Инновационная } \\
\text { стратегия }\end{array}$ & Эволюционная стратегия & $\begin{array}{c}\text { Адаптационная } \\
\text { стратегия }\end{array}$ & $\begin{array}{c}\text { Концентрационная } \\
\text { стратегия }\end{array}$ \\
\hline Внешняя среда & \multicolumn{2}{|c|}{$\begin{array}{l}\text { - Рост спроса и цен на продукцию (сырьевые } \\
\text { ресурсы) } \\
\text { - Доступность заемного капитала }\end{array}$} & \multicolumn{2}{|c|}{$\begin{array}{l}\text { - Падение спроса и цен на продукцию (сырьевые } \\
\text { ресурсы) } \\
\text { - Рост инфляции и стоимости заемного капитала }\end{array}$} \\
\hline Внутренняя среда & $\begin{array}{l}\text { - Рост производитель- } \\
\text { ности } \\
\text { - Рост мощности } \\
\text { - Снижение затрат }\end{array}$ & \multicolumn{2}{|c|}{$\begin{array}{l}\text { - Падение производительности } \\
\text { - Износ оборудования и технологий } \\
\text { - Доработка запасов }\end{array}$} & $\begin{array}{l}\text { - Рост производительности } \\
\text { - Рост мощности } \\
\text { - Отработка } \\
\text { благоприятных запасов } \\
\text { - Снижение затрат }\end{array}$ \\
\hline Цели стратегии & $\begin{array}{l}\text { - Освоение нового уровня } \\
\text { социально-экономиче- } \\
\text { ского развития } \\
\text { - Смена технологического } \\
\text { уклада }\end{array}$ & $\begin{array}{l}\text { - Повышение } \\
\text { конкурентоспособности } \\
\text { за счет технико- } \\
\text { технологических и } \\
\text { организационных } \\
\text { изменений }\end{array}$ & $\begin{array}{l}- \text { Сохранение } \\
\text { имеющихся } \\
\text { конкурентных } \\
\text { преимуществ } \\
\text { - Освоение новых } \\
\text { рынков }\end{array}$ & $\begin{array}{l}\text { - Сохранение } \\
\text { предприятия: } \\
\text { запасов (лицензий), } \\
\text { основного персонала, } \\
\text { оборудования }\end{array}$ \\
\hline $\begin{array}{l}\text { Экономические задачи } \\
\text { стратегии }\end{array}$ & $\begin{array}{l}\text { - Внедрение новых } \\
\text { технологий } \\
\text { - Освоение новой } \\
\text { ресурсной базы } \\
\text { - Освоение нового } \\
\text { продукта } \\
\text { Снижение затрат за } \\
\text { счет нового уклада }\end{array}$ & \begin{tabular}{|l|} 
- Внедрение технико- \\
технологических и \\
организационных \\
преобразований \\
- Снижение затрат за счет \\
внутренних резервов
\end{tabular} & $\begin{array}{l}\text { Сохранение } \\
\text { имеющихся } \\
\text { конкурентных } \\
\text { преимуществ } \\
\text { - Снижение затрат } \\
\text { за счет внутренних } \\
\text { резервов }\end{array}$ & $\begin{array}{l}\text { - Снижение затрат } \\
\text { за счет запасов, } \\
\text { вспомогательных } \\
\text { производств, } \\
\text { инфраструктуры } \\
\text { - Поддержание } \\
\text { работоспособности } \\
\text { основного производства }\end{array}$ \\
\hline $\begin{array}{l}\text { Социальные задачи } \\
\text { стратегии }\end{array}$ & $\begin{array}{l}\text { - Повышение стоимости } \\
\text { человеческого капитала } \\
\text { - Обеспечение оплаты } \\
\text { труда выше рыночного } \\
\text { уровня }\end{array}$ & $\begin{array}{l}\text { - Сохранение ключевого } \\
\text { персонала } \\
\text { - Обеспечение оплаты } \\
\text { труда выше рыночного } \\
\text { уровня }\end{array}$ & $\begin{array}{l}\text { - Сохранение ключевого } \\
\text { персонала } \\
\text { - Обеспечение оплаты } \\
\text { труда выше рыночного } \\
\text { уровня }\end{array}$ & $\begin{array}{l}\text { - Сохранение ключевого } \\
\text { персонала } \\
\text { - Сохранение оплаты } \\
\text { труда } \\
\text { - Минимизация } \\
\text { социальных конфлликтов }\end{array}$ \\
\hline $\begin{array}{l}\text { Динамика социальных } \\
\text { затрат (дс3) }\end{array}$ & $\begin{array}{l}\uparrow, \uparrow \uparrow \\
{\left[\mathrm{C} 3_{\min } ;+\infty\right]}\end{array}$ & $\begin{array}{l}\uparrow, \uparrow \uparrow \\
{\left[\mathrm{C} 3_{\min } ;+\infty\right]}\end{array}$ & $\uparrow\left[\mathrm{C} 3_{\min } ;+\infty\right]$ & $\mathrm{C}_{\text {min }} \rightarrow$ const \\
\hline $\begin{array}{l}\text { Динамика экономиче- } \\
\text { ских затрат (дЭ3) }\end{array}$ & $\begin{array}{l}\uparrow, \uparrow \uparrow \\
{\left[Э 3_{\min } ;+\infty\right]}\end{array}$ & $\begin{array}{l}\uparrow, \uparrow \uparrow \\
{\left[3_{\min } ;+\infty\right]}\end{array}$ & $\uparrow$ & $33_{\min } \rightarrow$ const \\
\hline $\begin{array}{l}\text { Горизонт планирова- } \\
\text { ния }\end{array}$ & Долгосрочный & Долгосрочный & $\begin{array}{l}\text { Краткосрочный } \\
\text { Среднесрочный }\end{array}$ & Краткосрочный \\
\hline
\end{tabular}

развития. Социальная составляющая стратегии должна содержать в себе алгоритм действий по созданию условий для самоактуализации в профессиональной деятельности, открывающих возможность работнику использовать и развить свои способности; показывать перспективы взаимодействия: поддержать уверенность в обеспечении благоприятных условий труда и перспективе профессионального роста у сотрудника; раскрывать механизмы формирования вознаграждения за работу в соответствии со стандартами оплаты и уровнем ожиданий субъекта $[17,18]$. Мотивационный механизм реализуется через распределение ресурсов, результатов труда, капитала между субъектами развития: персоналом и собственником. Выбор стратегии при распределении ресурсов определяется динамическими факторами внешней и внутренней среды.
Результаты работы и область их применения

На основе обобщения опыта проведения преобразований на предприятиях горной промышленности и тактики поведения в конкретной сложившейся ситуации сформулированы четыре принципиальные стратегии социальноэкономического развития, определяемые наложением циклов развития внешней и внутренней среды: концентрационная, адаптационная, эволюционная и инновационная. Правильный выбор стратегии позволяет менеджменту принимать рациональные управленческие решения: сохранять активы и работоспособность технологической подсистемы при снижении экономических потерь в условиях кризиса; нарастить эффективность и реализовать потенциал в благоприятных условиях. 


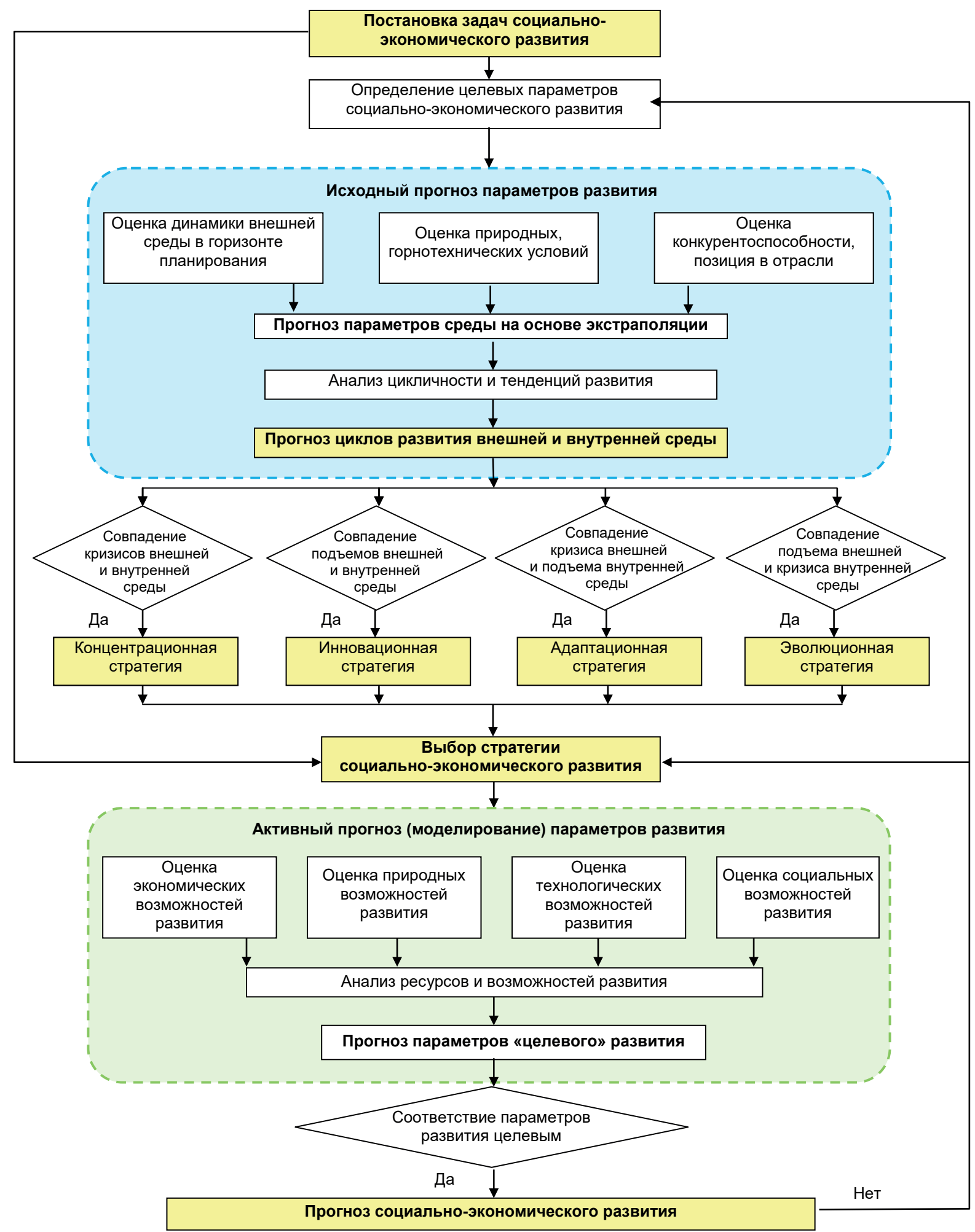

Рисунок 1. Алгоритм разработки стратегии социально-экономического развития промышленного предприятия.

Figure 1. Algorithm for developing a strategy for the socio-economic development of an industrial enterprise.

1. Концентрационная стратегия. Применяется при наложении кризисных фаз циклов внешней и внутренней среды. Целью стратегического управления предприятием является концентрация и сохранение «ключевых элементов» системы: технологии, основных производственных фондов, объема вскрытых запасов минерального сырья, ядра наиболее квалифицированного персонала. При сохранении «ключевых элементов» происходит количественное и качественное сокращение элементов, не участвующих в генерации добавленной стоимости: обслуживающие цеха, вспомогательное оборудование и т. д. Наибольшую сложность представляет сохранение сотрудников, способных не только выполнять свои функциональные обязанности 
в условиях жестких ограничений, но и обеспечивать реализацию антикризисных мер. Реализация концентрационной стратегии нацелена на обеспечение основной производственной функции (добыча полезного ископаемого), апослестабилизацииситуации-реализации потенциала и наращиванию объемов производства. При данной стратегии преобладают экономические интересы собственника по сохранению предприятия, социальные интересы реализуются через сохранение рабочих мест и приемлемого уровня заработной платы. При разработке стратегии необходимо выполнить прогноз распределения ресурсов после реализации антикризисных мер

2. Адаптационная стратегия. Актуальна для ситуации наложения фазы падения для внешней среды и фазы подъема внутренней среды. Целью стратегии является выход предприятия на новый продукт (новые рынки), либо сохранение конкурентоспособности за счет использования внутренних резервов техники и технологии. Развитие обеспечивается использованием адаптационных механизмов и действий, способных адекватно реагироватьнадестабилизирующеевоздействие факторов внешней среды, обеспечивая устойчивость функционирования и развития предприятия. Стратегия адаптационного развития включает в себя алгоритм выбора методов и способов формирования внутренних изменений, адекватных негативным воздействиям внешней среды. Дестабилизирующее воздействие факторов внешней среды компенсируется своевременным, адекватным и согласованным изменением в подсистемах горнодобывающего предприятия. Кризисные явления, сопровождаемые снижением спроса, требуют подключения адаптационных механизмов, в первую очередь, для технологической и социальной подсистем предприятия: преобразования, направленные на снижение себестоимости продукции, а также институциональные преобразования в части реализации социальных интересов через развитие персонала и поддержание инновационных инициатив, являются важной составляющей адаптационной стратегии, способной обеспечить выход предприятия на новый продукт, новые рынки, либо сохранить конкурентоспособность за счет использования внутренних резервов техники и технологии.

3. Эволюционная стратегия. Наиболее рациональна для наложения фаз падения для внутренней среды и подъема для внешней среды. Целью стратегии является повышение конкурентоспособности предприятия на основе стандартизации технологических процессов, отдельных операций, условий достижения и необходимого уровня производительности оборудования и труда. Как правило, стратегия обеспечивается организационными преобразованиями при проведении локальных техникотехнологических усовершенствований. Основой эволюционной стратегии является персонал, способный реализовать производственные резервы.

4. Инновационная стратегия. Может быть реализована при наложении фаз подъема для внешней и внутренней среды. Целью стратегии является значимое повышение конкурентоспособности при параллельном формировании системы производственных резервов.
Инновационная стратегия развития должна содержать две составляющие:

1. Создание, отбор и внедрение инноваций. Устойчивость и эффективность развития горнодобывающего предприятия может быть обеспечена только на основе регулярного внедрения организационных и технологических инноваций, ориентированных на устойчивое социально-экономическое развитие:

- через достижение согласованности действий между субъектами предприятия;

- усиление роли человеческого капитала - опыта и знаний ведущих специалистов, инженеров и пр.;

- регламентацию функций участников инновационной деятельности.

2. Программа создания сбалансированной структуры резервов. Реализуется для каждой из подсистем горнодобывающего предприятия при благоприятном прогнозе внешней и внутренней среды. Формирование резервов обеспечивает предприятию устойчивость развития для условий кризисных изменений внешней и внутренней среды [19].

Алгоритм разработки стратегии развития предусматривает три этапа (рис. 1):

1. Прогнозирование; включает формирование научно обоснованного представления о траектории и результатах социально-экономического развития, а также о его параметрах с учетом динамики внешней и внутренней среды;

2. Программно-целевое планирование; подразумевает выделение целей и приоритетов социальноэкономического развития, разработку комплекса мероприятий, направленных на их достижение, а также определение источников финансирования;

3. Стратегический контроль; связан с контролем реализации решений, достижением стратегических целей, а также мониторингом результатов социальноэкономического развития, включая параметры достигнутых показателей использованных ресурсов.

\section{Закиючение}

Долгосрочная конкурентоспособность и эффективность горных предприятий обеспечивается реализацией стратегии инновационного развития. Основные проблемы реализации этой стратегии связанны не с горно-геологическими и технико-технологическими особенностями конкретного предприятия, а с наличием управленческих несоответствий между техникоэкономическими возможностями и мотивационными механизмами, что требует совершенствования стратегия социально-экономического развития. Стратегический план должен быть не только согласован с целями собственника и его видением будущего, но и отражать мотивационный механизм для субъектов, реализующих стратегию: алгоритм действий по созданию условий для работника использовать и развить свои способности; механизмы формирования вознаграждения за работу в условиях повышенной неопределенности. Значимый рост эффективности и конкурентоспособности, а также переход горнодобывающего предприятия к устойчивому развитию обеспечивается сбалансированным распределением ограниченных ресурсов между 
социальными и экономическими целями на основании формирования стратегии социально-экономического развития. Распределения добавленной стоимости с отклонением от рациональных пропорций могут дать краткосрочные эффекты, но не создают основу для устойчивого развития в долгосрочном периоде. Сформулированы четыре принципиальные стратегии социально-экономического развития, определяемые наложением циклов развития внешней и внутренней среды: концентрационная, адаптационная, эволюционная и инновационная. Определение типа рациональной стратегии развития предприятия целесообразно начинать с анализа и прогноза динамики внешней и внутренней среды Правильный выбор стратегии позволяет принимать рациональные управленческие решения: в кризисных условиях - снизить экономические потери, сохранить активы предприятия и работоспособность технологической подсистемы; в благоприятных условиях - реализовать потенциал предприятия на основе роста эффективности и устойчивости его работы.

\section{ЛИТЕРАТУРА}

1. Bebchuk L. A., Cohen A., Hirst S. The agency problems of institutional investors // Journal of Economic Perspectives. 2017. T. 31, № 3. P. 89-102. https://doi.org/10.1257/jep.31.3.89

2. Трубецкой К. Н., Каплунов Д. Р., Рыльникова М. В., Радченко Д. Н. Условия устойчивого функционирования минерально-сырьевого комплекса России. Вып. 2 // ГИАБ. 2015. № 2. С. 318-319.

3. Артемьев В. Б., Захаров В. Н., Галкин В. А., Федоров А. В., Макаров А. М. Стратегия, тактика и практика инновационного развития открытых горных работ // Уголь. 2017. № 12. С. 6-19. http://dx.doi.org/10.18796/0041-5790-2017-12-6-19

4. Артемьев В. Б., Волков С. А., Лисовский В. В., Галкин В. А., Захаров С. И. Подходы кповышению конкурентоспособности угледобывающего предприятия и его персонала // Уголь. 2019. № 6. С. 4-9. http://dx.doi.org/10.18796/0041-5790-2019-6-4-9

5. Костарев А. С. Оценка резервов инновационного развития угледобывающего производственного объединения и влияние организационно-экономических отношений на их использование // Изв. УГГУ. 2020. Вып. 1(57). С. 208-217. http://dx.doi.org/10.21440/23072091-2020-1-208-217

6. Shvaiba D. Digitalization of Economic Processes and New Challenges in View of the Formation of a Motivational and Stimulating Trap // Bulletin of Science and Practice. 2020. Vol. 6(6). P. 235-239. (In Russ.) https://doi.org/10.33619/2414-2948/55/30

7. Галкин В. А., Макаров А. М., Кравчук И. Л., Лапаева О. А. Роль человеческого фактора в жизнеспособности горнодобывающего предприятия // Проблемы недропользования. 2016. Вып. 4. С. 189-197.

8. Wellmer F.-W., Scholz R. W. What Is the Optimal and Sustainable Lifetime of a Mine? // Sustainability. 2018. Vol. 10 (2). 480. https://doi. org/10.3390/su10020480

9. O'Callaghan T., Graetz G. Mining in the Asia-Pacific: Risks, Challenges and Opportunities. Cham: Springer International Publishing, 2017. 388 p. 10. Волков С. А. Инновационная активность и результативность человеческого капитала угольной компании // Регион: системы, экономика, управление. 2019. № 1 (44). С. 146-150.

11. Anderson R. W., Bustamante M. C., Guibaud S., Zervos M. Agency, firm growth, and managerial turnover // The Journal of Finance. 2018. T. 73, № 1. P. 419-464. https://doi.org/10.1111/jofi.12583

12. Крюкова А. А. Вопросы стратегического менеджмента в промышленности // Актуальные проблемы современной науки. 2012. № 2. С. 29-34.

13. Костарев А.С. Стратегическое планирование инновационного развития угледобывающего производственного объединения. М: Экономика, 2019. 173 с.

14. Shuck B., Roberts T. P., Zigarmi D. Employee Perceptions of the Work Environment, Motivational Outlooks, and Employee Work Intentions: An HR Practitioner's Dream or Nightmare? // Advances in Developing Human Resources. 2018. Vol. 20(2) P. 197-213. https://doi. org/10.1177/1523422318757209

15. Ансоффр И. Стратегическое управление: сокр. пер. с англ. / науч. ред. и авт. предисл. Л. И. Евенко. М.: Экономика, 1989. 519 с.

16. Каплан А. В. Управление социально-экономическим развитием горнодобывающего предприятия. М.: Экономика, 2015.270 с.

17. Галкина Н. В., Килин А. Б., Захаров С. И., Полещук М. Н., Росляков С. В. Методический подход к организации управления развитием горнодобывающего предприятия на основе повышения субъектности его персонала // Изв. УГГУ. 2020. Bып. 3(59). C. 155-162. https://doi. org/10.21440/2307-2091-2020-3-155-162

18. Lapaeva O. Conception of the socio-economic rationing as a basis for the transformation of the labour rationing in terms of the social and economic development of an enterprise // Economics: Yesterday, Today and Tomorrow. 2020. Vol. 10, issue 4A. P. 364-379. https://doi. org/10.21440/2307-2091-2020-1-196-207

19. Лапаев В. Н., Каплан А. В., Терешина М. А., Милославская К. С. Стратегии сбалансированного социально-экономического развития угледобывающего предприятия // Уголь. 2018. № 6(1107). С. 59-62. http://dx.doi.org/10.18796/0041-5790-2018-6-59-62 


\title{
Strategies for the socio-economic development of a mining enterprise
}

\author{
Aleksey Vladimirovich KAPLAN ${ }^{1 *}$, \\ Mariya Aleksandrovna TERESHINA ${ }^{2 * *}$ \\ ${ }^{1}$ LLC «NIIOGR», Chelyabinsk, Russia \\ 'LLC "STC-Geotechnology", Ekaterinburg, Russia
}

\begin{abstract}
Relevance. Ensuring the long-term competitiveness and efficiency of mining enterprises requires increasing the pace of development: the introduction of new technologies, the improvement of labor methods, the implementation of institutional transformations. However, the implementation of the innovation strategy does not occur systematically, at an insufficient pace, with an excess of resource costs and a systematic failure to achieve planned results, due mainly to subjective factors based on contradictions between economic goals and the social policy of the enterprise.

Purpose of the study: the formation of standard strategies for the socio-economic development of a mining enterprise, depending on the dynamics of the external and internal environment.

Research methods. In the course of the study, the methods of structural-functional analysis, abstract-logical modeling, socio-economic forecasting, production experiment and systems approach were used..

Results. On the basis of the study of the processes of transformation of the mining industry, the general problems hindering the innovative development of enterprises are highlighted. The main reason for such problems is managerial inconsistencies between technical and economic capabilities and motivational mechanisms. Based on the study of the transformation processes of mining enterprises, four standard strategies of socio-economic development have been developed that ensure the transition to sustainable development based on a balanced distribution of limited resources between social and economic goals.

Conclusions. The fundamental strategies of socio-economic development are determined by overlapping development cycles of the external and internal environment: concentration, adaptation, evolutionary and innovation. The correct choice of strategy allows making rational management decisions: in crisis conditions - to reduce economic losses, to preserve the assets of the enterprise and the operability of the technological subsystem; in favorable conditions - to realize the potential of the enterprise based on the growth of efficiency and sustainability of its work
\end{abstract}

Keywords: mining enterprise, strategy, innovation, socio-economic development, subjects, motivation, concentration, evolution, adaptation.

\section{REFERENCES}

1. Bebchuk L. A., Cohen A., Hirst S. 2017, The agency problems of institutional investors. Journal of Economic Perspectives, vol. 31, no. 3, pp. 89-102. https://doi.org/10.1257/jep.31.3.89

2. Trubetskoy K. N., Kaplunov D. R., Ryl'nikova M.V. et al. 2015, Usloviya ustoychivogo funktsionirovaniya mineral'no-syr'yevogo kompleksa Rossii. Vyp. 2. Gornyy informatsionno-analiticheskiy byulleten' (nauchno-tekhnicheskiy zhurnal), no. 2, pp. 318-319.

3. Artem'yev V. B., Zakharov V. N., Galkin V. A., Fedorov A. V., Makarov A. M. 2017, Strategiya, taktika i praktika innovatsionnogo razvitiya otkrytykh gornykh rabot. Ugol', no. 12, pp. 6-19. http://dx.doi.org/10.18796/0041-5790-2017-12-6-19

4. Artem'yev V. B., Volkov S. A., Lisovskiy V. V., Galkin V. A., Zakharov S. I. 2019, Podkhody k povysheniyu konkurentosposobnosti ugledobyvayushchego predpriyatiya i yego personala. Ugol', no. 6, pp. 4-9. http://dx.doi.org/10.18796/0041-5790-2019-6-4-9

5. Kostarev A. S. 2020, Otsenka rezervov innovatsionnogo razvitiya ugledobyvayushchego proizvodstvennogo ob"yedineniya $i$ vliyaniye organizatsionno-ekonomicheskikh otnosheniy na ikh ispol'zovaniye. Izvestiya UGGU. Vyp. 1(57), pp. 208-217. http://dx.doi.org/10.21440/23072091-2020-1-208-217

6. Shvaiba D. 2020, Digitalization of Economic Processes and New Challenges in View of the Formation of a Motivational and Stimulating Trap. Bulletin of Science and Practice, vol. 6(6), pp. 235-239. (In Russ.). https://doi.org/10.33619/2414-2948/55/30

7. Galkin V. A., Makarov A. M., Kravchuk I. L., Lapayeva O. A. 2016, Rol' chelovecheskogo faktora v zhiznesposobnosti gornodobyvayushchego predpriyatiya. Problemy nedropol'zovaniya, vyp. 4, pp. 189-197.

8. Wellmer F.-W., Scholz R. W. 2018, What Is the Optimal and Sustainable Lifetime of a Mine? Sustainability, vol. 10, issue 2, pp. 480. https://doi. org/10.3390/su10020480.

9. O'Callaghan T., Graetz G. 2017, Mining in the Asia-Pacific: Risks, Challenges and Opportunities. Cham: Springer International Publishing, 388 p. 10. Volkov S. A. 2019, Innovatsionnaya aktivnost' i rezul'tativnost' chelovecheskogo kapitala ugol'noy kompanii. Region: sistemy, ekonomika, upravleniye, no. 1 (44), pp. 146-150.

11. Anderson R. W., Bustamante M. C., Guibaud S., Zervos M. 2018, Agency, firm growth, and managerial turnover. The Journal of Finance, vol. 73, no. 1, pp. 419-464. https://doi.org/10.1111/jofi.12583 
12. Kryukova A. A. 2012, Voprosy strategicheskogo menedzhmenta v promyshlennosti. Aktual. probl. sovr. Nauki, no. 2, pp. $29-34$.

13. Kostarev A. S. 2019, Strategicheskoye planirovaniye innovatsionnogo razvitiya ugledobyvayushchego proizvodstvennogo ob"yedineniya. Moscow, $173 \mathrm{p}$.

14. Shuck B., Roberts T. P., Zigarmi D. 2018, Employee Perceptions of the Work Environment, Motivational Outlooks, and Employee Work Intentions: An HR Practitioner's Dream or Nightmare? Advances in Developing Human Resources, vol. 20(2), pp. 197-213. https://doi. org/10.1177/1523422318757209

15. Ansoff I. 1989, Strategicheskoye upravleniye: Sokr. per. s angl. / Nauchn. red. i avt. predisl. L. I. Yevenko. Moscow, 519 p.

16. Kaplan A. V. 2015, Upravleniye sotsial'no-ekonomicheskim razvitiyem gornodobyvayushchego predpriyatiya. Moscow, $270 \mathrm{p}$.

17. Galkina N. V., Kilin A. B., Zakharov S. I., Poleshchuk M. N., Roslyakov S. V. 2020, Metodicheskiy podkhod k organizatsii upravleniya razvitiyem gornodobyvayushchego predpriyatiya na osnove povysheniya sub"yektnosti yego personala. Izvestiya UGGU, Vyp. 3(59), pp. 155-162. https:// doi.org/10.21440/2307-2091-2020-3-155-162

18. Lapaeva O. 2020, Conception of the socio-economic rationing as a basis for the transformation of the labour rationing in terms of the social and economic development of an enterprise. Economics: Yesterday, Today and Tomorrow, vol. 10, issue 4A, pp. 364-379. https://doi. org/10.21440/2307-2091-2020-1-196-207

19. Lapayev V. N., Kaplan A. V., Tereshina M. A., Miloslavskaya K. S. 2018, Strategii sbalansirovannogo sotsial'no-ekonomicheskogo razvitiya ugledobyvayushchego predpriyatiya. Ugol', no. 6(1107), pp. 59-62. http://dx.doi.org/10.18796/0041-5790-2018-6-59-62

The article was received on November 11, 2020 